\title{
Medical Students' Experience: Community Engagement and Advocacy through Photovoice
}

Heather Charlotte Hunter, ' Deep Jaiswal, ' Brittany Cameron, ${ }^{1}$ Matthew J. To, ${ }^{1}$ Catherine Cox, ${ }^{1}$ Suzanne Kathleen Clarke, ${ }^{1}$ Cinera States, ' Ciaran Lane.'

About the Author: Heather Hunter is currently a thirdyear medical student of Dalhousie University, Halifax, Canada of a four-year program.
Submission: Jan 07, 2016

Acceptance: Mar 07, 2016

Publication: Apr 19, 2016

\section{The Experience}

Learning in medical school takes many forms including reviewing literature, attending lectures, and interacting with patients. Despite the various academic experiences in our curriculum, learning from the lived and personal experiences of marginalized communities, especially youth, is greatly lacking. This gap paints an incomplete picture of the social issues and health challenges that local communities experience. To address this, we engaged inner-city teenage youth in Halifax, Nova Scotia, Canada during the summer of 2014 in a discussion about what they felt makes a healthy community.

The team consisted of eight medical students who shared a common interest in community action, advocacy and art. We used a Participatory Action Research (PAR) approach for our project, specifically Photovoice. PAR's objectives of empowering participants, assessing community needs and assets, and taking action in the community best encompassed our goals. ${ }^{1-2}$ In Photovoice, participants use photography to express their views and facilitate critical discussions around their topic of interest. In this project, ten youth from two inner-city youth organizations captured their community's lived experiences pertaining to a variety of social issues. They then developed narratives that placed their photos into a critical social context and created a platform for community action. ${ }^{1-2}$

In this article, we summarize important lessons this project taught us as medical students about community engagement and advocacy.

Lesson \# 1: The Power of a Non-hierarchal Working Structure The intention to work in a leaderless structure had implications for how we worked with each other and the youth. Our group's emphasis was on finding ways to make the project work rather than keeping track of how much each individual contributed. We also focused on enabling people to assist in any way they could, including the youth, who were equal collaborators in our non-hierarchical framework. To develop a respectful partnership, we engaged in direct and clear communication with the youth. This set the stage for conversations about how the project should be run and how the information could be shared with the larger community. In short, we learned that having a common goal, good communication and trust between participants is critical for building a strong foundation for collaboration.

Lesson \#2: Being Flexible with Our Approach in Order to Meet Evolving Needs

At various times throughout this project, we needed to modify our approach to meet the needs of the community. For example, we initially considered inviting youth to the university for workshops on "how to do photovoice" but realized that for many, this geographic shift into unfamiliar territory could be a barrier to participation. Instead, emphasis was placed on meeting the youth within their communities. At times, it was important to modify our language. For example, when we first asked youth "what does health mean to you?" their response included things like "not having a broken leg". We realized that to get at broader conceptions of health, we had to use an accessible line of questions like "what does a healthy and safe community look like to you?"

\section{Lesson \#3: Building New Relationships While Maintaining} Old Ones

As the results of the photovoice project came in, it was clear that the youth had important things to say about their communities. We felt that their insights should be shared, and that youth should take a leading role in presenting their photographs and narratives to the larger community. In order to do so, we sought the youths' perspective on how their community could be involved. We then had to build relationships with the larger community. This entailed reaching out to local organizations and businesses to help promote an art-exhibit where the youths' work would be displayed. Local politicians, advocates, and community members were invited, and the feedback we received was overwhelmingly positive. At the event, an interactive space allowed attendees to leave hand-written comments and we heard things like "I'm sorry I didn't fight for your playground and community" and "the pictures made me think of how we can help more". From this, we learned about the importance of communication, collaboration and building momentum in a community for positive change.

${ }^{1}$ Faculty of Medicine, Dalhousie University, Halifax Regional Municipality, Nova Scotia, Canada. 


\section{Experience}

\section{Lesson \# 4: Putting Ethics into Practice}

When deciding to exhibit the project, we had to reflect on the ethical implications of our actions. Since the photographs and narratives belonged to the youth, we wanted to avoid appropriating their work and exploiting lived experiences. Continuously seeking permission and input from youth groups was an essential part of this process. This served as a lesson in critical thinking about ethical implications of community action.

In conclusion, we felt fortunate for the opportunity to engage youth through the PAR approach. We gained a better understanding about social issues facing our local community and reinforced the importance of building relationships, listening to communities and 'empowering people to speak for themselves'. This experience will make us more effective advocates for change, informing how we practice medicine and utilize partnership approaches with our patients.

\section{References}

1. Wang C, Burris MA. Empowerment through photo novella: portraits of participation. Health Educ Q. 1994 Summer;21(2):171-86.

2. Wang C, Burris MA. Photovoice: concept, methodology, and use for participatory needs assessment. Health Educ Behav. 1997 Jun;24(3):369-87.

\section{Acknowledgments}

Special thanks to the youth and program coordinators at the Needham Community Centre and St. Ceorge's YouthNet for participating in the project.

Conflict of Interest Statement at Funding

We would like to thank the Dalhousie Medical Students' Society, Nova Scotia Public Interest Research Group, and Medical Humanities program at Dalhousie University for providing funding for the Photovoice project.

Author Contributions

Conceptualization, Data collection, Data analysis and interpretation, Critical revision of the manuscript, Approval of the final version: $\mathrm{HCH}$, DJ, BC, MJT, CC, SKC, CS, CL. Writing: HCH, DJ.

Cite as:

Hunter HC, Jaiswal D, Cameron B, To MJ, Cox C, Clarke SK, et al. Medical students' experience: community engagement and advocacy through Photovoice. Int J Med Students. 2016 Jan-Apr;4(1):38-9. 